\title{
SÀÁGUA AND BAUMTROG ON PRACTICAL RATIONALITY
}

\author{
$*$ \\ DAVID BotTING \\ Flat 1, 38 Westfield Rd. Yeovil \\ SOMERSET, BA21 3DA, U.K.
}

\begin{abstract}
In "Practical Rationality at Work - A New Argumentation Model" (2018, pp.193-230) Sàágua and Baumtrog offer what they call "a new ideal model of integrated practical reasoning and argumentation." I will argue that their only really original contribution is a reconceptualization of argumentation schemes as producing pro tanto reasons, and such a reconceptualization is both wrong-headed in itself and makes their model less integrated than other models, not more. In fact, their work is itself an example of bad practical reasoning.
\end{abstract}

Keywords: practical reasoning; argumentation; means-end rationality 


\section{Introduction}

"Practical Rationality at Work - A New Argumentation Model" is a long paper and impossible to summarize in a few words. Its proclaimed aim is to give an "integrated ideal model of practical reasoning and argumentation." In this introductory section I will give and criticize their general theoretical framework and conclude that not only does it fail to achieve that aim, but also the means Sàaua and Baumtrog choose to achieve that aim are actually counter-productive; their model is itself an example of bad practical reasoning, as it involves choosing means that cannot possibly, for broad theoretical reasons irrespective of the detail, achieve their ends. In the later sections I will enter into detailed criticism of the argumentation schemes they offer and show that they do not all conform to the same pattern, sometimes because they conclude with different kinds of reason, and sometimes because of a mismatch between what the scheme concludes and the question to which the scheme is meant to be providing an answer.

The first task then is to lay out the model and explain what is meant by their claim that it is an "integrated ideal model of practical reasoning". The model is given on (2018, p.199):

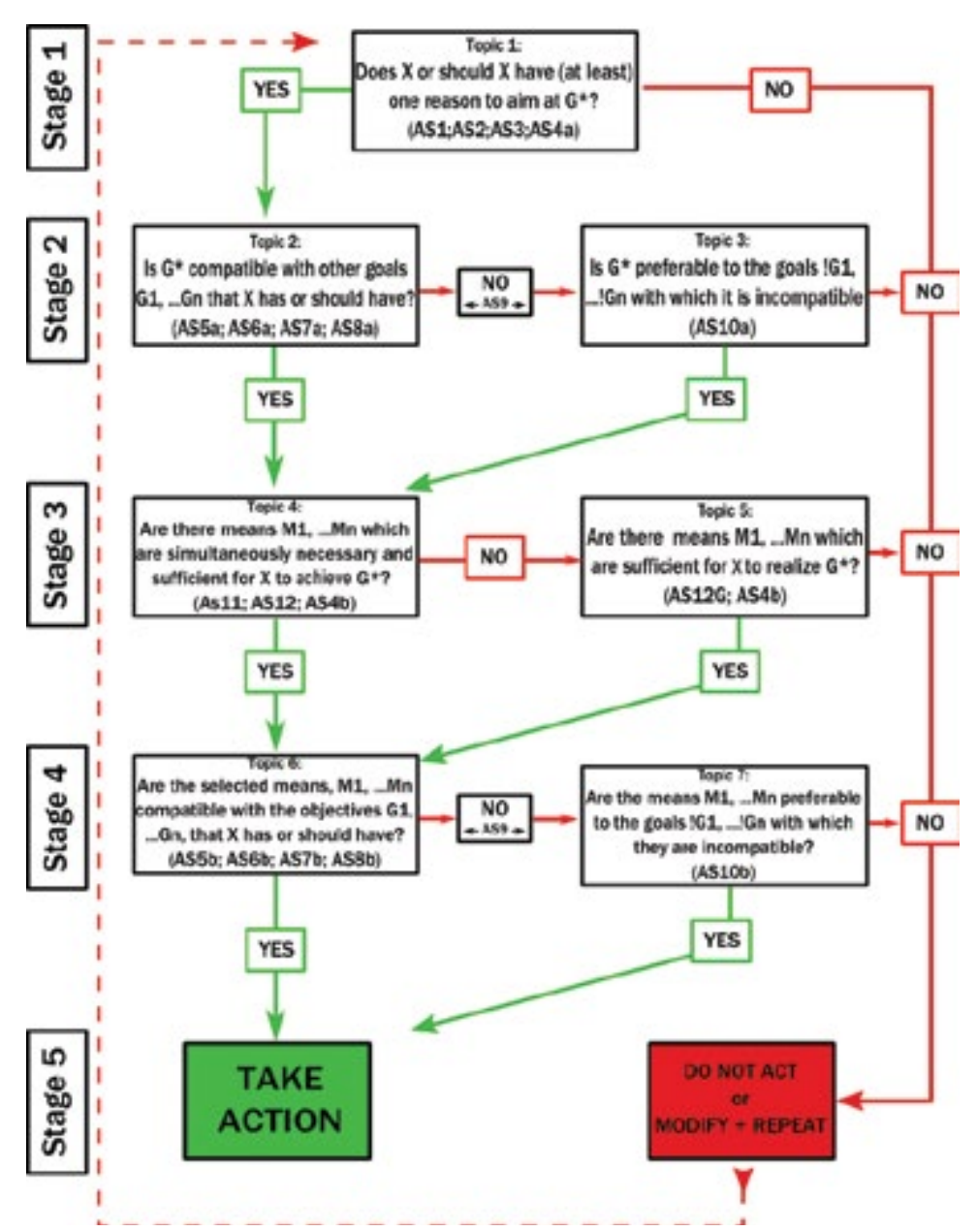

Figura 1 
An agent navigates the model by answering each topic question in turn "Yes" or "No", the answers to which determine at the final stage whether the agent acts or not. These answers depend in turn on the agent's answers to the critical questions of the argumentation schemes appealed to with respect to each topic question: "In order to reasonably answer the Topic Questions, the agent must have reasons supporting their answer. Those reasons can be specified using an appropriate argument scheme. The model indicates what we consider to be the basic, necessary schemes to justify an answer to each one of the Topics" (Sàágua and Baumtrog, 2018, p.227). More than one argumentation scheme can be appealed to for any question, and the same argumentation scheme can be used in different stages. Most of the rest of Sàágua and Baumtrog's paper is a comprehensive list of the argumentation schemes involved and their critical questions.

In what way or ways is this model an "integrated ideal model of practical reasoning and argumentation", and how is it different, if it is different, from other models?

The first difference worth noticing is that whereas most models of practical reasoning (e.g., utility theory) are models of means-end reasoning and start at stage 3, Sàágua and Baumtrog's model has an earlier stage in which the reasoner's choice of goals is included as something for which reasons must be given, which reasons must stand the test of critical questioning. In Sàágua and Baumtrog's words (2018, p.200) "We think that the assumption of the objectives themselves should be an object of reasoning and argumentation - and not only the choice of means", and this is re-iterated in their conclusion: "With the aim of providing a model extending beyond mere instrumental reasoning, we have included consideration of the motivations for aiming at a goal as the first step in explicit practical reasoning and argumentation" (Sàágua and Baumtrog, 2018, p.227). This is one way in which they take their model to be integrated: moral considerations or in their word "ethics" are explicitly included in the model. However, as it turns out, making "the assumption of the objectives themselves ... an object of reasoning and argumentation" only allows for a limited kind of rational criticism, as the critical questions are explicitly prohibited from questioning the choice of goals on material grounds: it does not allow the judgment "That choice of goal is wrong" but at best "That choice of goal is internally inconsistent with other goals you have or should have." It will not rule out from being a reasonable choice of ends the very things that, as we will see in the next section, they want to rule out.

Another way in which Sàágua and Baumtrog take their model to be integrated, and indicated in the quote above where they say "argumentation or reasoning", is that the stages can be interpreted as either stages of argumentation or stages of reasoning. As can be seen, there are five stages, and at each stage one or two topic questions, to which the answer is either "Yes" or "No". Each question is to be answered by appeal to an argumentation scheme 
or schemes. These questions and schemes can be taken as appealed to in an argumentative discourse or in monological reasoning. In Sàágua and Baumtrog's words (2018, p.194): "For those viewing the model with a mind to argumentation, ... think in terms of commitments interlocutors have and can be held accountable for. Viewing the model as an instance of reasoning ... view the model in terms of attitudes that connect to reasons in an inferential process." This claim to integration, as integrating argumentation and reasoning, is true as far as it goes, but I would deny that this is a difference between their model and other models.

Their last claim to integration is that it integrates elements from dialectical models with elements from BDI models. This might not be obvious from the diagram, but it occurs because the arguer or reasoner is required to have only a pro tanto reason to answer "Yes" to the Topic Question, and the argumentation schemes appealed to are taken to generate such pro tanto reasons. ${ }^{1}$ However, I will show that this is actually inconsistent with the preceding claim to integration. By explicitly including an element from BDI models, or to be more specific, by building it into the very form of the schemes that their conclusions are pro tanto reasons, it is difficult to see how such schemes can be interpreted as or incorporated into any other model than a model of reasoning. If argumentation schemes are like this, they are not models of argumentation. But I will argue in section 3 that this innovation of theirs, which is their only real claim to originality, is misguided for all sorts of reasons not limited to the one just mentioned.

In three ways, then, their model includes more than other models would, or so Sàaua and Baumtrog claim, appealing to this novelty as justification for proposing their model as an improvement on those already available. If this extended scope of the model is a false ideal, or not really an extension but found also in other models, then by their own account their whole proposal is lacking in justification. I will argue that Sàágua and Baumtrog's innovations fail for one or other of these reasons. Let me be more specific: by an "integrated ideal model of practical reasoning and argumentation" the main (but not only) thing that they seem to mean by "integrated" is that the model can represent alternatively a piece of argumentation or a token of reasoning (by interpreting the model's components in different ways), but I will argue that this is to be found in models quite generally and not unique to their model, and by "practical reasoning" they mean more than just means-end reasoning but include also reasoning about the goals the agent aims to achieve, which reasoning the

\footnotetext{
1 There is a curiosity here connected to the fact that the Topic Question at Stage 1 simply is "is there a reason?" The argumentation schemes at Stage 1 justify answering "Yes" because their conclusions simply are those reasons, that is to say, those conclusions are truth-makers for an affirmative answer rather than providing further reasons for an affirmative answer. In short, they are not reasons for believing that we have a reason, but just are that reason. This is not so for the other topic questions, where the reasons generated by the argumentation schemes function straightforwardly as epistemic reasons rather than as truth-makers. This is a minor quibble, though.
} 
model aims to bring into the scope of critical questioning, but I will argue that this is a false ideal. For these reasons, their proposal is lacking in justification.

I will largely set aside the extension of the model to include evaluation of one's choice of goals, ${ }^{2}$ that is to say, the integration of practical reasoning and ethics, and focus instead on their claims to having integrated reasoning and argumentation-I will argue on completely general grounds that such a degree of integration is a false ideal and fails to take account of norms of reasoning that are not norms of argumentation and vice versa, but that not only does their model fail to achieve this false (and actually impossible) ideal, it actually fails to reach a level of integration that such a model ought to have and that other models do have. Nonetheless, the model might still have value if those parts, in particular the argumentation schemes they use, were correct. But I will argue that in so far as these argumentation schemes offer anything novel, they are wrong, both on general grounds and in points of detail. Therefore, the model is less than the sum of its parts and fails to meet its stated aim, and the parts are either unoriginal or, when they are original, wrong, and moreover their model combines those schemes in a way that often conflates instrumental reasons associated with means (by which I mean practical 'Pascalian' reasons favouring being in a particular psychological state, where being in that state is instrumental to bringing about the intended end) with moral reasons associated with ends (in which I include subordinate ends alongside the ultimate values they promote). The unavoidable conclusion is that their whole proposal is lacking in justification.

\section{2. "Practical reasoning" and the choice of ends}

Let us look at some examples of "practical reasoning" to see what verdict Sàaua and Baumtrog want their model to deliver. We will see that this motivates adoption of an objective conception of reasons. But, as I suggested above, the model can only deliver the verdict Sàágua and Baumtrog want if these objective reasons can be criticised on material grounds, and this is something that they do not want to allow out of fear of being seen to be saying “These ethical principles are the right ones!" When they talk about goals the reasoner should have, they do not mean those goals that are in conformity with any substantive list of ethical principles or values, but merely internal consistency with the reasoner's own value-system, and it should be noted that nowhere in the critical questions is the reasoner's value-system held up to scrutiny.

2 For criticisms of this aspect in respect to an earlier paper of Sàágua and Baumtrog see Hitchcock (2016). I will make some further comments on this in the conclusion. 
The Nazis engaged in practical reasoning when they reasoned that using Zyklon B was a more efficient means of achieving their end of eliminating the prisoners in concentration camps than other alternatives. As an example of means-end reasoning, this is a perfectly good piece of reasoning. Moreover, given their aims, the Nazis had instrumental reason to kill their prisoners with Zyklon B. But it seems that Sàágua and Baumtrog would not want to say that this is good practical reasoning, and this is their motivation for making evaluation of the original choice of goal an explicit aim of the model ${ }^{3}$ - something has gone very wrong with our reasoning if this is our goal, and I think they would deny that the Nazis had good reason to kill their prisoners with Zyklon B (or at all, for that matter).

In saying this, though, they cannot believe that psychological states function as providing reasons, or at least it is not reasons of this kind that are being referred to in the verdict (which they want the model to give) that the Nazis had no reason to kill their prisoners with Zyklon B, for on such a subjective view of reasons all that is needed in order for an agent to have a reason is for the agent to desire the aim, no matter what the aim or how arbitrary the desire. The Nazis do have a reason to kill their prisoners on this subjective notion of a reason, as their desire to kill Jews gives them one. So, what issues from the model as the reason acted on is not this kind of subjective reason. By "reason", then, Sàágua and Baumtrog appear to mean the kind of reasons that are generated by (or simply are) facts rather than by psychological states of the agent, that is to say, an objective notion of a reason. To illustrate: they say ' $\mathrm{X}$ is thirsty' is a reason (a consideration that counts in favour) for $\mathrm{x}$ to (intend to) drink water" (Sàaua and Baumtrog, 2018, p.197). Note that they do not say that X has a reason to drink what he believes to be water.

On this objective conception of reasons, a thirsty man does not have a reason to drink a glass of petrol if he mistakenly believes it to be water, but on the contrary has a reason not to drink it, his belief that it is water notwithstanding. ${ }^{4}$ However, his belief that it is water will be a premise in his practical reasoning and when he concludes (mistakenly) that he has a reason to drink from the glass, we cannot fault his practical reasoning when he dies from poisoning. Nor can we fault the Nazis' practical reasoning when they mistakenly think that they have reason to kill Jews with Zyklon B, but objectively do not. This illustrates the difference between a subjective and an objective conception of reasons. Objective reasons, unli-

\footnotetext{
3 Baumtrog's preferred example is the mass murders of Anders Breivik (Baumtrog, 2015). Unfortunately, it will turn out that this evaluation of the original choice of goal does not extend to saying that the end is morally wrong, which is surely what we want to say, and which I think is what they want to say too. The kind of critical questioning and evaluation that is brought to bear on the choice of ends turns out to be very limited.

4 That this is Sàágua and Baumtrog's conception of reason is further supported by their appeal to Scanlon (1998), as this is certainly Scanlon's view.
} 
ke subjective reasons, do not as such motivate the reasoner, as the reasoner might be quite unaware of having such a reason, and if he is unaware of such a reason he is entirely unable to act upon it, so objective reasons do not explain a reasoner's actions either. Objective reasons function normatively as a standard against which we can evaluate a reasoner's actions-when we say, as Sàágua and Baumtrog want to say, “The Nazis did not act (or value) reasonably" this means "The Nazis did not act in accordance with objective reasons."

Insofar as an agent's practical reasoning accords to the model, he may think that he has reasons when in fact he does not, and insofar as the model is meant to be an ideal model of the agent's reasoning this does not matter much since the reasoning can be good either way, and the difference is only in the premises-if it were having the aim or desire that provided the reason then it is not clear how we could ever be in error about this and so the premise will be true. For example, it would be strange if we could somehow be mistaken about whether we believe that the glass contains water. We can, in contrast, be mistaken about whether the glass actually does contain water, so when the glass does not contain water the premise that it does will be false. But the reasoning itself is good and the agent is instrumentally rational either way.

So, this conception of reasons is not a problem as such, since believing that he has an objective reason and his actually having an objective reason is a distinction that the reasoner himself is unable to make. The reasoner takes himself to have objective reasons, and for him this explains why drinking what is in the glass is the right thing to do, though it is the subjective reasons (e.g., his normative belief that he has such and such an objective reason) that motivates and hence explains his actual behaviour. There are two kinds of explanation here, one normative and one causal. It is the subjective reasons that explain what we do when we act on a reason, because it is these that motivate, and play some kind of causal role in, our actual behaviour. But this is not what we are normally asking for when we ask someone why they act in a particular way. For instance, when we ask someone why they raised their arm, we do not expect them to answer "Well, there was a certain brain-event that activated the muscles in my arm and caused it to rise." This is explanation of a kind, a causal explanation, but not what was sought, and we might quite justifiably think that the person answering this way has misunderstood the question. What we want and expect when we ask this question is the normative reason, and it is the objective reasons that determine whether this is or is not normatively the right thing to do and explains why we do it. If we asked the petrol-drinker why he drank what was in the glass he would not give the causal explanation in terms of subjective reasons, and if he did we are likely to answer "That is not what I meant!" - what he gives, and what we would accept in response, is a normative explanation and the normative reason, and it is this kind of reason that the petrol-drinker 
means when he says, laying out his reasoning, that he has "reason" to drink what is in the glass. The petrol-drinker is sincere, and has argued entirely correctly, but on a false premise. If we convince him his premise is false he can still say "Well, I thought I had that objective reason" and that will still explain his behaviour and why he did what he did, but he will now be giving a causal explanation and not a normative explanation.

If we actually have the objective reasons that we think we do, we will always do the right thing, and quite correctly take ourselves to be doing the right thing. The problem is that however scrupulous an agent may be to try and believe only what is true there is always the possibility of being substantively wrong; since it is a fact that is providing the reason and not something like a desire or even a normative belief, it is always possible for either of the disagreeing parties to be mistaken about it. By using an objective conception of reasons Sàágua and Baumtrog seem to want to allow for just this possibility and would want to say that the Nazis' choice of ends is substantively wrong, but they seem to want to say this without making any substantive assumptions of their own, and in the end they settle for insisting that the reasoner subject his choice of ends to close critical scrutiny and keep their fingers crossed that the reasoner thereby discovers some lacuna or defect in his assumptions. If Sàágua and Baumtrog really want their model to deliver the opposite verdict on the Nazis, the way to do so is to criticize this premise on the material grounds that it is false, which an objective conception of reasons allows them to do. Their reluctance to do this, presumably on the grounds that they do not want to be seen as favouring one set of substantive ethical principles over others simply because those principles are their own, and instead allowing only criticism of the choice of goals on other than material grounds and thereby laying the blame for the choice of bad goals on bad reasoning, leaves the adoption of an objective conception of reasons without any point as they could have done this with a subjective conception of reasons. Having practical premises that can be materially false is only useful if you are allowed to say that they are materially false.

But I have digressed slightly. The main point is that although they do not say so explicitly Sàágua and Baumtrog are adopting an objective conception of reasons, and must do so in order to be able to question the premises from which the Nazis, for example, argued; I am just not as optimistic as they seem to be about how much such questioning can actually achieve when those questions ask only for the agent's reasons for accepting those premises and not the material truth of those premises. If an agent's value-system is consistent, I do not see how any critical questioning that does not make value judgments opposed to those of the agent is going to show that that value-system and that choice of ends is wrong, and when we come to the critical questions it is noticeable that the reasoner only needs to show that he has reasons for thinking that his goal will promote whatever he positively values, even if 
it is something like racial purity. The critical questions can pick up on when the reasoner is factually wrong about his goal promoting his value, or on when he is factually right but has poor reasons for thinking so, but do not pick up on morally egregious goals as such.

These objective reasons, including reasons for subordinate goals, are not instrumental reasons. The facts that make killing Jews a bad thing to do and give us objective reason not to kill Jews (whether we know this or not) do not say that it is bad on the grounds that it is a means to something else which we disvalue. Even if there is a "something else", say the general value of human life, which we appeal to as our reason against killing Jews, this is because respecting Jewish life just is a case of respecting human life and so a subordinate goal, and not a means by which we respect human life. Now, it might be (and probably is) the case that we are more likely to respect human life if we assume not killing Jews as one of our goals than if we did not, and if so, there is an instrumental reason too not to assume this as a goal. But this is a 'practical' or 'Pascalian' reason insofar as it does not actually matter what the content of the goal is; ${ }^{5}$ if Murphy's Law applied and making this assumption was actually counter-productive and led to more killing of Jews there could be instrumental reason to make it our aim to kill Jews, but the moral reason would still obviously be to not kill Jews, and it is because of this reason that we would have the instrumental reason to assume killing Jews as our aim, though we would not have, or even believe that we have, reason to act on this aim and actually kill Jews.

So, there is a certain amount of ambiguity in asking whether we have a reason to assume something as a goal, as it might mean a moral reason or it might mean an instrumental reason of the practical kind, in analogy to the difference between having reasons for $p$ 's being true ("epistemic" reasons) and reasons for being in the psychological state of believing $p$ ("non-epistemic" reasons, e.g., positive consequences). When they talk about "assuming something as a goal" Sàágua and Baumtrog could be thinking of "assuming" as a voluntary act of adopting a particular practical attitude for which there can be non-epistemic reasons, or they could mean something more like a belief for which non-epistemic reasons - although they could exist - cannot really affect what beliefs we have. ${ }^{6}$ In fact, I think that at some points their reasoning relies on assuming's being a practical attitude, and at other points being a cognitive attitude. Of course, usually these things go together as luckily Murphy's

5 It is a state-given reason rather than an object-given reason.

6 We might think, truly, that believing that God exists will allow us to live a more meaningful life, but we would not believe that God exists on these grounds for the simple reasons that it provides no grounds whatever for thinking this proposition to be true. We may, however, adopt a practical attitude towards the proposition that God exists to act as if it were true. 
Law does not apply, and it might seem that this is a nit-picking difference. However, it is important to keep the differences clear for two reasons.

One is that sometimes the argumentation schemes are best interpreted as providing moral reasons (when the choice of ends is being considered) and sometimes as providing practical reasons, so the schemes ought to be revised to make clear what kind of reasons their conclusions are talking about. But even if this were done, having two types of reasons in the model would lead to problems later in the reasoning: when we are weighing up which of our multiple aims we ought to assume, it seems that it is the practical kind of reason that is at issue, as we want to know the conditional probability of the value being promoted having assumed something as a goal. But although we ought to assume this as a goal, it is not necessarily the case that we ought to act on this goal, the goals that we ought to act on being determined by the moral reasons - that is to say, the reasons supporting the truth of "Killing Jews is wrong" - rather than the practical reasons, and it is the moral reasons that we need to appeal to if we judge the Nazis' practical reasoning as a case of bad reasoning. As mentioned above, we might be in the unlucky situation that the conditional probability of our actually killing Jews is higher if we assume as our goal not to kill Jews than if we assume as our goal to kill Jews. Then we ought to assume killing Jews as our goal, taking "assuming" here as a practical attitude, but we ought not to kill Jews, and the reason why we ought to assume killing Jews as our goal is because we ought not to kill Jews. This would be a bizarre and unfortunate condition to be in, but it would not be inconsistent.

Another is that we cannot get two reasons, or increase the support for choosing a particular end, by adding a practical reason for adopting that end (i.e., assuming it as a subjective goal) as an aim to the moral reason for endorsing that end. When the question is whether we should endorse the end, only the moral reason is relevant, and the fact (assuming it is a fact, which I have pointed out it might not be) that we may be more likely to act in conformity with our endorsed ends if we assume them as goals, does not give us an extra moral reason to endorse the end. Similarly, when the question is whether we should adopt the end, only the practical reason is relevant, as this is determined by how likely we are to satisfy that end once we have adopted it, and nothing else. Unfortunately, I will show that some of Sàaua and Baumtrog's argumentation schemes conclude with practical reasons and treat "assuming as an end" as a practical attitude, and some do not, and this causes them to miscount the number of reasons in answering their topic questions.

For these reasons putting both kinds of evaluation in the same model is a dubious virtue and false ideal; although there is nothing wrong with questioning our original choice of ends, having both in the same model encourages us to mix up different kinds of reasons and different kinds of norms of reasoning that are better kept apart. As already said, there 
was nothing wrong with the Nazis' practical reasoning, or the petrol-drinker's. Both were instrumentally rational, whether the reasons are taken to be objective or subjective, and I do not see why Sàágua and Baumtrog want their model to deliver the opposing verdict; whether reasoning is good or not does not depend on whether the premises are true or not, and we do not consider a model of deductive reasoning to be defective on the grounds that it does not tell us whether the premises of a valid deductive argument are true. Anyway, as we have seen, the premises' being false does not actually enter into the evaluation of the reasoning-only the agent's reasons for accepting the premises does.

So much for "practical reasoning". As I said, it is not the primary focus of this paper. The distinctions made here between objective, subjective, and practical reasons will only gain in importance when we come to analyse the argumentation schemes.

\section{Integrating reasoning and argumentation}

I will now show that being "integrated" in the sense of being a model of both argumentation and reasoning would also be of dubious merit if it were actually possible. It is not possible, however, because there are norms of good reasoning that are not norms of good argumentation, and vice versa. It is a false ideal to try to integrate both in the same model (even more so than the dubiousness of including evaluation of means and ends in the same model). Some integration is possible and even unavoidable. What I object to is their claiming such integration as a special virtue of their model that is lacked by others, and taking this in part to justify their work. This is simply not true. Insofar as their model might be thought to be integrated, all models of reasoning or of argumentation are integrated. But I will argue that their model is not even as integrated as this, that in fact by explicitly incorporating reasons in the schemes, the model is less integrated than other models, as such an element resists any alternative interpretation.

Let's go back to our Nazi example to illustrate what they mean when they claim that their model is integrated. The argument that the Nazis would use would be something like:

(Desire Premise) We want to kill prisoners.

(Means-End Belief) Using Zyklon B is a more efficient method of killing prisoners than the alternatives available to us.

(Conclusion) We intend to use (kill prisoners by using) Zyklon B.

The first premise is a desire, the second a belief, the third an intention. This is the basis of the $\mathrm{B}$ (elief) D(esire) I(ntention) model. We could imagine this easily as an argumentative discourse:

CONCENTRATION CAMP OFFICER: We have too many prisoners. We need to kill some of them. 
SUBORDINATE: How? If we shoot them all it will waste ammunition. We need a more efficient way of killing them.

CONCENTRATION CAMP OFFICER: We'll gas them.

SUBORDINATE: That's not very efficient either.

CONCENTRATION CAMP OFFICER: I've heard of this stuff called Zyklon B. We can kill large numbers with only small amounts. It's cheap and easy to get.

SUBORDINATE (enthusiastically): Sounds ideal!

Equally we can imagine the officer arguing with himself "We need to kill more prisoners, and most of the ways are too inefficient. Zyklon B is the most efficient. So, I will kill prisoners by gassing them with Zyklon B." The same elements - the aim of killing prisoners, the efficiency of Zyklon B with respect to this aim, the decision to kill prisoners by this means - figure in all three.

It is, then, to some extent obvious that all three will have a similar structure and the same structural units, which merely have to be interpreted differently, as Sàágua and Baumtrog say. In this respect 'integratedness' is a natural aim for a model. But it is worth noting that it is because of the structural similarities between these things, and not because of a virtue of the particular model chosen, that there is this 'integratedness'. All models of reasoning will be models of argumentation for the reason that, and to the (limited) extent that, argumentation and reasoning are structurally the same.

Even so, not all models are the same, as there are norms of reasoning that are not norms of argument or argumentation: reasoning well is not identical to possessing a sound argument, since, for example, if one is not basing one's belief on the argument but on something else, or is not justified in believing that the argument is valid, even though it is, then one has not reasoned well, but there is nothing wrong with one's argument, which is perfectly sound, or with one's performance in argumentative discourse if one stated the argument's premises and then its conclusion (although there may be other reasons why, in this situation, one has not argued well). Also, one may have reasoned well even when those other norms are satisfied but the argument is not sound, that is to say, it has false premises. Basing one's beliefs on arguments that are valid and known to be valid is a norm of believing but not of argument, while having true premises is a norm of arguments but not of reasoning. Next, it is often claimed to be a norm of argumentative discourse that the arguers only use premises that the other party would agree with, or at least not use premises the other party would disagree with, but there is no such norm for reasoning or for argument. So, a model of good reasoning might have things that a model of argumentation would not have, and vice versa, some of which are relevant to practical rationality and some which are not (for example, if the subordinate failed to address his superior correctly or failed to 'take his turn' 
then this is an error of performance in argumentative discourse, but of little or no relevance to practical rationality). Hence, Audi (2006) distinguishes between assessing the argument (by largely logical and material criteria), assessing the reasoning (by what he calls inferential criteria) and assessing the rationality of the doxastic states (by what he calls epistemic criteria). If being integrated is taken to imply that reasoning and argumentation can both be assessed by the same norms, even if interpreted differently, then it is making a substantive, and false, assumption; it would not be to a model's advantage to be 'integrated.7 As I will argue, Sàágua and Baumtrog's model does not in fact achieve this level of integration; the error is in claiming that it does when it does not and in claiming it to be a special virtue of their model not shared by others that it does so, when it would not be a virtue anyway even if it were achievable, and to the limited extent that it is achievable, it would not be a special virtue of their model anyway because all models are integrated to this extent as being so integrated follows directly from the structural similarities of what is being modelled. So again, even if Sàaua and Baumtrog trimmed back their claims about integration (or if I have been uncharitable in attributing to them a stronger claim about integration than they really meant), it would still be of no special virtue of their model that it is integrated to this extent, since all models are integrated to this extent.

In response, Sàágua and Baumtrog would probably point to their modification of argumentation schemes as illustrative of the way they intend to combine elements from commitment models and the BDI models used by theorists of reasoning. This is admittedly original and is what I will turn to now.

Of special interest to practical reasoning are considerations that count in favour of or against assuming some goal or performing some action. One thing that they are explicit on is the inferential character of these reasons. Reasons are contributing and pro tanto (Sàágua and Baumtrog, 2018, p.198). Moreover, they (or at least those that are proximate to assuming the goal/performing the action) are the outcomes of instances of plausible reasoning codified in argumentation schemes. Seeing argumentation schemes as producing pro tanto reasons is one of two innovations that they make to argumentation schemes, and

7 Audi is interested in assessing practical reasoning and does not consider argumentation in discourse. My point (borrowed from Audi) is that although when someone reasons they are tokening the argument, the soundness of the argument tokened does not guarantee the goodness of the reasoning. Insofar as an integrated model fails to recognize this, it is a defect in the model. So, the advantages of 'integratedness' in a model should not be overstated, although it is certainly true that many of a model's components should easily lend themselves to re-interpretation in the ways described. It should be noted that Audi (2008) is cited by Sàágua and Baumtrog so one can only assume that they have read it.

Perhaps these differences would be attenuated if, as in most models (e.g., utility theory), it were only means-end rationality (which does not consider, for example, the truth of the reasoner's premises) that they wished to assess, but the model is specifically intended to go beyond this. 
is an explicit inclusion of a BDI component in the model. ${ }^{8} \mathrm{I}$ will argue that far from making their model more integrated, this move actually makes their model less integrated. But the proposal has difficulties in itself independently of whether it serves their wider purpose.

First of all, by their own account, Sàágua and Baumtrog "consider argumentation to turn on the notion of conflict, and thus conceive of it as a dialectical situation" and that "argumentation begins when one or more parts of the process of reasoning come into conflict - it is the contestation of reasoning or its conclusion" (Sàágua and Baumtrog, 2018, p.195-6). Use of an argumentation scheme is supposed to resolve this conflict by transferring the acceptability of its premises to its conclusion. But if the conclusion is just a pro tanto reason, the conflict is not resolved. For there to be a conflict in the first place there must be (softening the "must be" to "could be" would not substantially change the objection) pro tanto reasons for and against the conclusion, so for an argumentation scheme to tell you that there is a pro tanto reason for the conclusion only unhelpfully re-iterates what you already knew.

8 The other is that instead of the normal set of critical question with "Yes/No" answers, they insert a pair of critical questions for each of the scheme's premises with the aim of eliciting reasons for and against it. Here is their explanation (Sàágua and Baumtrog, 2018, p.202):

If you have a separate, critical Other asking the critical questions, then the wording of the questions can be less stringent in light of the opportunity for the Other to 'press harder' - so to speak - if the answerer does not provide a satisfactory answer. In the case where you are the only one responsible for asking and answering the critical questions, a more carefully worded question will make it harder to provide an unsatisfactory answer. As such, we find the wording of the questions is of great importance and have avoided using critical questions with only 'Yes' or 'No' answers.

$\cdots$

... [W]e have designed the questions as a pair of questions, the first of which asks for an explanation of the inferential term's use and the second of which challenges it. Both parts are necessary, in our view, for the critical questioning of the inferential term to be adequate.

I find the notion of an "inferential term" obscure, but we do not need to dwell on it. I am not too concerned with this particular innovation. I will only make two remarks in passing.

The first is that the point of asking and answering questions whose answers are "Yes" and "No" is to transfer the burden of proof from one arguer to another. It is not clear to me whether the critical questions expressed this way does this, especially if the reason given by the answerer is pro tanto. (I think that they take these reasons to be pro tanto as well as the reason produced by the scheme, although it is not clear). The reservations I will express in a moment about the power of pro tanto reasons to conclude a stage of reasoning (in the model) also bear on their power to resolve the question of who has the burden of proof. Does a pro tanto reason resolve anything, apart from the question of whether one has a pro tanto reason (which, as it turns out, is the topic question at stage 1 of their model)?

The second is that what Sàágua and Baumtrog appear to have in mind in taking argumentation schemes to produce pro tanto reasons is that the conclusion of the argumentation scheme mentions a pro tanto reason, and not that the premises of the scheme produce pro tanto reasons for its conclusion lalthough they would not necessarily deny the latter). It is not clear whether they would hold all pro tanto reasons to be the outcomes of argumentation schemes (certainly they do not believe that all reasons whatsoever are contributing and pro tanto). If they did they would be faced with a regress, since the critical questions elicit reasons (I continue to assume these are pro tanto reasons) for the premises of the argumentation scheme, so if the only way we could get those reasons and answer critical questions were through using another argumentation scheme (which they explicitly allow for in particular instances) and answering that scheme's critical questions, we would need an infinite number of instances of argumentation schemes, or an argumentation scheme with no critical questions to stop the regress. I am guessing, then, that they would agree that there are some pro tanto reasons that an arguer just has, and that the arguer does not have to appeal to an argumentation scheme for such cases. 
Second of all, an argumentation scheme is meant to represent how someone would actually reason (being a kind of 'naturalized logic') and we do not in general reason that we have reasons. When we reason deductively, for example, we do not reason "I have a conclusive reason to believe my conclusion if I believe my premises, and I do believe my premises; therefore, I have a conclusive reason to believe my conclusion" and then proceed to act on this reason, but rather more simply "If my premises are true then my conclusion is true, and my premises are true; therefore, my conclusion is true." Reasons-talk is generally used from an external standpoint to describe someone else's reasoning or to formulate normative principles of reasoning (e.g., reason transmission principles, about which later), or when we want to abstract away from what we are reasoning about. We might reason in a second-order way that refers to reasons (and reason transmission principles) explicitly, but it certainly would not be very natural.

Now in Stage 1 of their model Sàágua and Baumtrog want to answer the question "Does $\mathrm{X}$ have (or should X have) at least one reason to assume $G^{*}$ ?" which, quite obviously, requires $\mathrm{X}$ to reason about whether he has a reason. Here, any conflict over whether $\mathrm{X}$ has a pro tanto reason to assume $\mathrm{G}^{\star}$ is settled by saying "Yes!" and exhibiting it to the disagreeing party. But this is part of the content of the reasoning task, whereas having the argumentation schemes conclude with having a reason (to assume $\mathrm{G}^{*}$ in these cases) is part of the formal structure of the scheme, and in fact of all schemes as Sàágua and Baumtrog have them, irrespective of content and what question they are answering.

Sàaua and Baumtrog have effectively taken the content of one of their topic questions as determining the structure of argumentation schemes generally, and this turns those schemes into second-order reasoning in cases where this is unnatural; or at least, it is only the content of their topic question at Stage 1 that makes having this kind of conclusion natural, and (going back to my first objection) it is only this question that a pro tanto reason can settle, precisely because it is the pro tanto reason that the topic question asks for. In short, the reason why these two objections do not seem to apply at Stage 1 is simply because of the topic question asked in Stage 1. Success at stage 1 may have misled Sàaua and Baumtrog into thinking that their modification works at all stages and in general, no matter what the content of the question. It does not.

Third of all, the argumentation schemes have detachable conclusions, which is to say that they resemble narrow-scope principles of rationality like:

(Reasoning Modus Ponens): $\mathrm{B}(p) \& \mathrm{~B}($ if $p$ then $q) \rightarrow \mathrm{R}(\mathrm{B}(q))^{9}$ 
This leads to boot-strapping problems that Broome and others have pointed out. ${ }^{10}$ Now, Sàágua and Baumtrog would counter-argue that what they mean is not analogous to this but instead to

(Reasoning Modus Ponens $\left.{ }^{\star}\right): \mathrm{R}[\mathrm{B}(p)]$ \& $\mathrm{R}[\mathrm{B}($ if $p$ then $q)] \rightarrow \mathrm{R}(\mathrm{B}(q)$ )

Although the premises of the argumentation schemes do not themselves mention reasons, such reasons are elicited by the critical questions, so this is not boot-strapping. I would accept this. ${ }^{11}$ But there are additional complications when it is a case of transferring reasons from ends to means:

(Practical Reasoning Modus Ponens): $\mathrm{D}(p) \& \mathrm{~B}($ if $p$ then $q) \rightarrow \mathrm{R}(\mathrm{I}(q))^{12}$

Suppose that although I desire to work, and in order to work I need to get out of bed, but that, as a matter of fact and despite my desire, I am not going to work. In those circumstances, do I have a reason to get out of bed, or even a reason to have the intention to get out of bed? The example is contentious. My complaint is that I think Sàágua and Baumtrog take it for granted that I do have such a reason. ${ }^{13}$ Perhaps they would say that since they take the inference to be defeasible, it would not be inconsistent with the argumentation scheme for it to give either answer, that is to say that they would endorse

10 The classic counter-example is that believing something gives you a reason for believing just because you believe it, since this is $\mathrm{B}(p) \& \mathrm{~B}($ if $p$ then $p) \rightarrow \mathrm{R}(\mathrm{B}(p))$.

11 I still have reservations about this. The reason indicated by the $\mathrm{R}$ in the consequent seems to be the objective reason, so even after critical questioning this would only imply that if I have reasons to believe that $p$ and reasons to believe that $p$ implies $q$, I therefore have reasons to believe that I have an objective reason to believe $q$. But it is not clear that I do have this second-order reason, as the same objections apply as before; if attaching the reason to the consequent is troubling then it is not clear that insisting that the reasoner has reasons for thinking that the antecedents hold is going to abate that problem, as it is still not clear that the consequent holds, that is to say, that the reasoner has reasons for believing that he has an (objective) reason. And even if I do have reasons for believing that I have an objective reason, it doesn't follow that I actually do have an objective reason. For example: I have a reason to believe that the glass contains water, and a reason to believe that if it is water, it is potable, but do I have a reason to believe that what is in the glass is potable on that conception of a reason in which, as I have pointed out earlier, I do not have a reason to drink it if in fact it contains petrol? But perhaps they would counter-argue that someone's reasons for believing $p$, for example, just are their reasons for believing that they have an objective reason to believe $p$. In that case, I think you do get Reasoning Modus Ponens* and we just have to bear in mind that one can be mistaken about what objective reasons one has. In the scenario described, the petrol-drinker does not have an objective reason to think that the glass contains water (though he has reason to believe that he has this objective reason) any more than he has an objective reason to believe it contains something potable, or to drink it if thirsty lalthough, again, he has reasons to believe that he has these reasons). So, Reasoning Modus Ponens* is still valid and I will set this reservation aside.

12 In words, if you desire that $p$ and believe that $p$ implies $q$ (i.e., $q$-ing is a necessary means to bringing about $p$ 's being true), then you have a reason to intend to $q$.

13 The issue is perhaps easier to see when expressed with 'oughts'. I ought to work today, and it is necessary to get out of bed in order to work. But as a matter of fact I am not going to work when I get out of bed. Is it still the case that I ought to get up? The model of Fairclough and Fairclough (2012), which heavily influences Sàágua and Baumtrog's model, expresses its conclusion in terms of such 'oughts' and seems oblivious to the problem here. My point is that this is not uncontentious, and although Sàágua and Baumtrog do not talk in terms of 'ought' I think they need to address this issue too. 
(Practical Reasoning Modus Ponens $\left.s^{\star}\right): \mathrm{R}[\mathrm{D}(p)] \& \mathrm{R}[\mathrm{B}($ if $p$ then $q)] w \mathrm{R}(\mathrm{I}(q)$ )

Or perhaps they would say that, while I am lying in bed, it is correct practical reasoning to intend to get up, even if as a matter of fact I do not work after I have got up.

But there is a general problem in this area. By traversing the model one topic at a time, it is presumed that if all goes well an action will result. But all that the argumentation schemes can generate is a pro tanto reason, and this only defeasibly, and the best that can be said for such an undefeated pro tanto reason is that it hasn't been defeated so far, either by other pro tanto reasons or by the scheme's defeasibility conditions. A pro tanto reason is simply not strong enough either to lead to action or resolve a difference of opinion (or, more arguably, resolve the question of who has the burden of proof during the critical questioning). Also, what licenses the move to the last stage in the model (to be shown shortly) seems implicitly to be stronger than what licenses the moves between the previous stages. The implication is that once you have taken all the pro tanto considerations into account, the one left standing will be an all things considered reason (i.e., the net result after all the pro tanto considerations for and against have been weighed against each other), and an all things considered reason admittedly would be strong enough. But then we have to suppose that there are some argumentation schemes whose conclusions are all things considered reasons, or we have to suppose that there is some reasoning that is not represented in the model by which the pro tanto reason is made into an all things considered reason, and it is not clear what this reasoning could be, since a pro tanto reason can always be defeated in principle, and only follows defeasibly from the premises to boot-even if you have considered all the other reasons so far, the best you can say from this is that the reason hasn't in fact been defeated yet; one may still rationally prefer to wait than to act.

Or if we take the argumentation scheme to model commitments, what we get in the final stage is a "a discursive commitment that one intends to perform some act" (Sàágua and Baumtrog, 2018, p.194). Such a discursive commitment is only a commitment relative to that particular dialectical situation. We cannot detach any kind of all things considered commitment from this, as there may be other dialectical situations in which one would not have this commitment. In fact, we may be in this other dialectical situation at the same time as we are in the first; since we may be in more than one dialectical situation at a time, that is to say, be having a reason-giving exchange with more than one set of interlocutors at a time, one would simultaneously have a discursive commitment to act relative to one set of interlocutors and a discursive commitment not to act, or not have a discursive commitment to act, relative to another. Now, one may say that as long as one is in one of those situations, that situation provides at least a pro tanto reason. But then we have gone in a circle, as such a reason will not make reasonable a decision to act, but only make acting justifiable to one particular set of interlocutors (and possibly unjustified to another). 


\section{A Critique of "Practical Rationality at Work"}

I will go through each of the five stages and the argumentation schemes provided for them. I will argue that the schemes do not always produce the same kind of reason, some only providing instrumental or subjective reasons. I will also argue that many of the schemes are reducible to the same argumentation scheme, and that it is consequently wrong to think of these different schemes as providing numerically distinct reasons.

a. Stage 1, Topic Question 1: Does X have (or should X have) at least one reason to assume $\mathrm{G}^{\star}$ ?

Four argumentation schemes are given for this stage (Sàágua and Baumtrog, 2018, pp.204208). More than one of these argumentation schemes can be used, which means, according to Sàágua and Baumtrog (2018, p.228), that there can be up to four reasons in Stage 1 for advancing to Stage 2 by answering the topic question affirmatively.

\section{Argumentation Scheme 1. Assumption of Objectives by Teleology (AS1)}

Premise 1: $\mathrm{X}$ has $\mathrm{G}+$ as its finality.

Premise 2: $\mathrm{G}^{\star}$ belongs to $\mathrm{G}+$.

Therefore, plausibly

Conclusion: There is a reason for $\mathrm{X}$ to assume $\mathrm{G}^{*}$.

Critical Questions for Argumentation Scheme 1

CQ1: How does G+ really correspond to the finality of X? How can $\mathrm{G}+$ not correspond to the finality of $\mathrm{X}$ ?

CQ2: How is $\mathrm{G}^{\star}$ really a particular case of $\mathrm{G}+$ ? How could $\mathrm{G}^{\star}$ not be a particular case of $\mathrm{G}+$ ?

\section{Argumentation Scheme 2. Argument from Positive Values (AS2)}

Premise 1 : value $\mathrm{V}$ is positive $(=\mathrm{V}+)$.

Premise $2: \mathrm{V}+$ positively values $\mathrm{G}^{*}$.

Therefore, plausibly

Conclusion: There is a reason for $\mathrm{X}$ to assume $\mathrm{G}^{*}$.

\section{Critical Questions for Argumentation Scheme 2}

CQ1: What reasons are there for attributing a positive value to $\mathrm{V}$ ? What reasons could count against attributing a negative value to $\mathrm{V}$ ?

CQ2: What reasons are there for the positive evaluation of $\mathrm{G}^{\star}$ by $\mathrm{V}+$ ? What reasons are there for $\mathrm{G}^{\star}$ not to be positively evaluated by $\mathrm{V}+$ ? 
Argumentation Scheme 3. Argument from Positive Consequences (AS3)

Premise 1: If $\mathrm{G}^{*}$ is realized by $\mathrm{X}$, then the consequences $\mathrm{K} 1, \ldots, \mathrm{Kn}$ will occur.

Premise $2: \mathrm{K} 1, \ldots, \mathrm{Kn}$ are to be valued positively.

Therefore, plausibly

Conclusion: There is a reason for $\mathrm{X}$ to assume $\mathrm{G}^{*}$.

Critical Questions for Argumentation Scheme 3

CQ1: What makes it plausible that $\mathrm{G}^{\star}$ has $\mathrm{K} 1, \ldots, \mathrm{Kn}$ as consequences? How could $\mathrm{G}^{\star}$ not have $\mathrm{K} 1, \ldots, \mathrm{Kn}$ as consequences?

CQ2: Why should $\mathrm{K} 1, \ldots, \mathrm{Kn}$ be positively valued?

How could $\mathrm{K} 1, \ldots, \mathrm{Kn}$ not be positively valued?

\section{Argumentation Scheme 4. Argument from Ability (AS4a)}

Premise 1: $G^{\star}$ should be positively valued.

Premise 2: $\mathrm{X}$ has the ability to realize $\mathrm{G}^{\star}$.

Premise 3: X's ability to realize $G^{\star}$ is a necessary/enabling condition for the realization of $\mathrm{G}^{*}$.

Therefore, plausibly,

Conclusion: There is a reason for $\mathrm{X}$ to assume $\mathrm{G}^{*}$.

\section{Critical Questions for Argumentation Scheme 4a}

CQ1: How does $\mathrm{X}$ have the ability to realize $\mathrm{G}^{\star}$ ?

What could prevent $X$ from realizing $G^{\star}$ ?

CQ2: To what extent is the assumption of $\mathrm{G}^{*}$ by $\mathrm{X}$ a necessary/enabling condition for the realization of $\mathrm{G}^{*}$ ?

Which y exists (such that $y \neq x$ ) whose ability to realize $G^{*}$ is a necessary/enabling condition for the realization of $\mathrm{G}^{\star}$ ?

Commentary: Each critical question is expressed by a pair of questions, the first member of each pair aimed at eliciting X's reasons for thinking that the corresponding premise ${ }^{14}$ is true while the second member aims at eliciting X's reasons for thinking that it is false. Note, though, that reasons do not enter into the premises themselves; according to the schemes, $\mathrm{X}$ has a reason to assume $\mathrm{G}^{\star}$ if the premises are true whether he believes those premises for good reasons or not, or even if he does not believe them at all (unless, perhaps, such cases are meant to be ruled out by the defeasibility conditions). As such, we get an appeal to a reason in the conclusion when there is no reason explicitly referred to in the premises, which state only

14 In most cases, CQ1 corresponds to/questions Premise 1, CQ2 corresponds to/questions Premise 2, and so on, though this is not always the case. 
facts. This is not necessarily a problem if facts can be reasons, so the form of the schemes is more evidence that Sàágua and Baumtrog are committed to this objective conception of reasons. Of course, when $\mathrm{X}$ appeals to the scheme in his reasoning he must believe the premises, and if he does not believe the premises for good reasons but draws the conclusion anyway, his reasoning will be rationally criticisable. X might have an objective reason but not be rational in believing that he does, or he might be rational in believing that he has an objective reason when he does not. In order to advance to the next stage, $\mathrm{X}$ must be reasonable in believing that he has an objective reason whether he does so in fact or not. As far as it goes, then, the critical questions express conditions of adequacy for reasoning according to the scheme.

Even so, I would deny that these are properly called argumentation schemes. Repeating a point made earlier, an argumentation scheme should be able to settle a disagreement, which is to say it should be able to determine, even if only temporarily and provisionally, which side of an argument an arguer should settle on when there are reasons on either side. To be told that there is a pro tanto reason on one side clearly does not do this, as this was granted from the outset; if there are reasons on either side, a fortiori there is reason on one side, and use of the argumentation scheme has not progressed the disagreement at all. ${ }^{15}$

Let's look at the schemes in detail, starting with AS1. First, we might ask what Premise 1 ("X has G+ as its finality") even means. In their example $\mathrm{X}$ is "NATO", G+ is "contribute to world peace and security", and $G^{*}$ is "helping Ukraine increase its defensive power." Contributing to world peace and security is defined as NATO's mission and, to use their curious term, "finality". In some cases (though probably not here) it might be constitutive of something being $\mathrm{X}$ that it has $\mathrm{G}+$ as an aim. As such it is difficult to see how any very illuminating answer can be given to the question "How does G+ really correspond to the finality of X?" beyond "That is how X is defined" or "It is stipulated that G+ is the finality of X." And the answer to "How can G+ not correspond to the finality of X?" is "It can't." Boiled down, CQ1 simply asks "Is Premise 1 true?" The same can be said of CQ2 in respect of Premise 2.

It should be noted that there is no question here of whether G+ is a "finality" that X should have, nor, consequently, is there an objective reason for $\mathrm{X}$ to assume $\mathrm{G}+$ let alone $\mathrm{G}^{\star}$; yet the

15 I would argue that the way they are presented these schemes are less like argumentation schemes than reason transmission principles. A simple example of such a principle that is relevant to practical reasoning is that if I have a reason for an end, and a certain means is sufficient for me to achieve that end, then I have a reason to carry out that means las in Practical Reasoning Modus Ponens given above). This takes one premise in which "reason" is explicitly mentioned and one where no reason is appealed to in order to conclude with a reason. (Note, again, that on the objective conception of having a reason I have a reason to carry out the means even if I am ignorant of its being the means for the end in question.) Generally, transmission principles take one normative premise and one nonnormative premise in order to draw a normative conclusion. Apart from AS1, the argumentation schemes in stage 1 all seem to have one normative premise (that something is valued or to be evaluated positively), another premise (or premises) that is non-normative, and conclude with the normative claim that $\mathrm{X}$ has a reason (to assume $\mathrm{G}^{*}$ ). 
mere fact that $\mathrm{X}$ has this finality is taken to be enough to provide a reason just as an agent's mere having of a desire, even an arbitrary one, is enough to provide that agent with a reason to satisfy that desire and ultimately act on it. The reason named in the conclusion of AS1 thus seems to be a merely subjective ${ }^{16}$ reason, even though it is a reason for endorsing a goal $\mathrm{G}^{\star}$ rather than a course of action. Probably the idea is that insofar as the topic question asks about goals X actually has as well as those $\mathrm{X}$ should have, AS1 provides a reason for taking X to actually have $\mathrm{G}^{*}$ as a goal irrespective of whether X should have it as a goal or not. My objection would then be that the topic question itself involves different kinds of reason but treats them as the same. Also, since the Nazis could just as easily have named the racial purity of the Aryan race as their "finality", by extending the question to include goals $\mathrm{X}$ simply has, the model allows for exactly the kind of practical reasoning that Sàágua and Baumtrog want to say is bad. AS1 explicitly rules in the very thing that they want to rule out (unless the hope is that it is ruled out later because of conflicting with other goals, goals that $\mathrm{X}$ should have, about which more later).

Or if it is to be supposed that there is objective reason for X's having G+ as an aim then it seems that this can only be because $\mathrm{G}+$ is positively evaluated, in which case AS1 collapses into AS2 or AS3. It might be thought that in answering the critical questions to AS1 it is quite permissible to appeal to other schemes, and thus that this is not necessarily a defect; we appeal, for example, to AS2 in answering CQ1, and the reason provided by AS2 is percolated upwards, so to speak. But the critical questions do not ask anything about whether having G+ as a finality is to be valued. Either AS1 concludes with a subjective reason that X simply has, or it is dispensable and should be replaced with an instance of AS2 or AS3. In neither case (though for different reasons) should the reason concluded by AS1 be added to the reason concluded by AS2 or by AS3, in one case because the reasons are different in kind, and in the other case because the reason concluded in AS1 is effectively the same as that concluded in AS2/3 - they would effectively be the same reason, and if we added them together, we would effectively be double-counting the same reason.

In fact, I will argue later that including goals that $\mathrm{X}$ merely has is a mistake and leads to boot-strapping. Having a goal cannot provide a reason for having that goal or acting on it, any more than having a belief can provide a reason for having that belief. To be more precise, it is a mistake given their goal of wanting to say that certain reasonings like those of the Nazis, although instrumentally rational, are bad. If the goal is to give conditions of adequacy for instrumental rationality itself it is not a mistake, but simply reflects the fact that we can reason practically even about goals that we merely have even when we should not have those goals and perhaps even believe we should not have those goals. 
Let's look at AS2 next. In analogy to AS1, the Critical Questions ask for reasons for the truth of the two premises. It is not clear what reasons $\mathrm{X}$ is supposed to have for attributing a positive value to $\mathrm{V}+$, except to subordinate $\mathrm{V}+$ to a yet further value; for 'ultimate' values I don't see that any very illuminating answer can be given to CQ1. In disanalogy to AS1, the reason named in AS2's conclusion is not a subjective reason; it is not enough for X simply to desire that $\mathrm{G}+$ be the case or have $\mathrm{G}+$ as a stipulated aim in order for there to be a reason for $\mathrm{X}$ to assume $\mathrm{G}^{*}$, or even for $\mathrm{X}$ to think that he has such a reason.

As for AS3, it seems to reduce to AS2. If some consequences are to be evaluated positively (Premise 2 of AS3) then there must be some positive value or values $\mathrm{V}$ (Premise 1 of AS2) that evaluate those consequences positively, and if $V$ evaluates $G^{*}$ 's consequences positively, it seems like it must evaluate $G^{\star}$ itself positively (Premise 2 of AS2). Perhaps it might be argued that bad things sometimes have good consequences, but that we should not for that reason call those bad things good. But I think that AS2 should call $\mathrm{G}^{*}$ good (that is to say, $\mathrm{V}+$ should evaluate $\mathrm{G}^{\star}$ positively) in this context, as we would still in this case want to draw the conclusion that there is a reason for $\mathrm{X}$ to assume $\mathrm{G}^{*}$. Thus, I do not see how the premises of AS3 can be true without the premises of AS2 being true. This redundancy is harmless to a large extent but may deceive us into thinking that there are more reasons than there really are, two when there is really only one. Unless the idea is that for each positively evaluated consequence there is a further reason to assume $\mathrm{G}^{\star}$, but AS3 does not have this result (though perhaps it should be modified so that it does).

AS4a is, by their own admission, a new argumentation scheme. The first thing to notice is that its Premise 1 (" $G^{*}$ should be positively valued") actually follows from the premises of AS2, from which AS2's conclusion also follows. Hence, insofar as we take AS2's conclusion and AS4a's conclusion to be the same, that conclusion follows by virtue of Premise 1 alone, and Premises 2 and 3 are redundant; Sàágua and Baumtrog (2018, p.208) seem to say as much themselves when they note that they take Premise 1 to have already been established by AS2 or AS3. But perhaps we should not take them to be the same conclusion. Sàaua and Baumtrog say $(2018$, p.208) that AS4a concludes to there being a reason for X rather than any other agent to assume $G^{*}$, because $X$ uniquely has the ability to bring $G^{*}$ about, and this reason can be added to the reason provided by AS2 or AS3. But this seems like an instrumental reason. If $\mathrm{G}^{*}$ is likely to be brought about or occur without X's agency then X does not have this kind of reason to assume $G^{*}$, or so they seem to say, and this is true insofar as one is generally (though not always, as I have pointed out) more likely to bring $G^{\star}$ about once one has assumed it as one's goal, provided that one has the ability to bring it about. It is a Pascalian, practical, state-given kind of reason for the practical attitude of making something one's goal, rather than a moral, object-given reason for the cognitive attitude of valuing that thing. 
The reasons named in the conclusion of AS1 and AS4a are not the kind of reasons by which one is allowed to move from Stage 1 to Stage 2, or if they are it is in virtue of being reasons for $\mathrm{X}$ to assume $\mathrm{G}^{*}$ on the basis of $\mathrm{G}+$ being a goal $\mathrm{X}$ actually has, which is not going to rule out the very thing that they want to rule out and that the use of objective reasons is designed to rule out. Only AS2 and AS3 are relevant, as only these provide objective reasons, and they are effectively the same argumentation scheme. Or perhaps it is only the instrumental reason that ought to count, so it is AS4a that we should keep and AS2 and AS3 that are redundant, but then, as I have indicated, it is not necessarily the case that we would want to end up acting to achieve this goal; even though there might be a practical reason to assume killing Jews as an aim, this is not an aim that we should act on or even desire to act on. The aims that we want to end up acting on are those that we actually endorse, which is to say, those for which we think that there is an objective moral reason because they promote values. So, I think it is AS4a that must be rejected after all. Either way, there can only really be one reason, and not four, for answering "Yes" to the topic question. ${ }^{17}$

a. Stage 2, Topic Question 2: Is $G^{\star}$ compatible with other goals G1, . , Gn that $\mathrm{X}$ has or should have?

There are four argumentation schemes relevant to Stage 2 and this topic question.

\section{Argumentation Scheme 5. Argument from Negative Values (AS5)}

Premise 1: the value V is negative (= V-).

Premise 2: V- negatively values $\mathrm{G}^{\star} / \mathrm{M}^{*}$.

Therefore, plausibly,

Conclusion: There is a reason for $\mathrm{X}$ not to assume $\mathrm{G}^{\star} / \mathrm{M}$.

\section{Critical Questions for Argument Scheme 5}

CQ1: What reasons are there for attributing a negative value to $\mathrm{V}$ ? How could V not have a negative value?

CQ2: What reasons are there for the negative evaluation of $\mathrm{G}^{*} / \mathrm{M}^{*}$ by $\mathrm{V}-$ ? How could $\mathrm{G}^{\star} / \mathrm{M}^{\star}$ not be negatively valued by $\mathrm{V}-$ ?

\section{Argumentation Scheme 6. Argument Contradicting Positive Values}

Premise 1: Value $\mathrm{V}$ is positive $(\mathrm{V}+)$.

17 With the qualification that there can be a number of positive consequences. This has nothing, however, to do with the number of argumentation schemes that can be appealed at a particular stage, as Sàágua and Baumtrog would have it. 
Premise 2: $\mathrm{G}^{\star} / \mathrm{M}^{\star}$ contradicts (or inhibits) $\mathrm{V}+$.

Therefore, plausibly

Conclusion: There is a reason for $\mathrm{X}$ not to assume $\mathrm{G}^{\star} / \mathrm{M}^{*}$.

Critical Questions for Argument Scheme 6

CQ1: What reasons are there for attributing a positive value to $\mathrm{V}$ ? How could $\mathrm{V}$ not be valued positively?

CQ2: What reasons are there to indicate $\mathrm{G}^{\star} / \mathrm{M}^{\star}$ contradicting (inhibiting) $\mathrm{V}+$ ? How could $\mathrm{G}^{\star} / \mathrm{M}^{\star}$ be congruent with $\mathrm{V}+$ ?

Argumentation Scheme 7. Argument from Negative Consequences (AS7)

Premise 1: If $\mathrm{G}^{*} / \mathrm{M}^{*}$ is realized by $\mathrm{X}$, the consequences $\mathrm{K} 1, \ldots, \mathrm{Kn}$ will occur.

Premise $2: \mathrm{K} 1, \ldots, \mathrm{Kn}$ are to be negatively valued.

Therefore, plausibly

Conclusion: There is a reason for $\mathrm{X}$ not to assume $\mathrm{G}^{\star} / \mathrm{M}^{\star}$.

\section{Critical Questions for Argument Scheme 7}

CQ1: What makes it plausible that $\mathrm{G}^{\star} / \mathrm{M}^{\star}$ has $\mathrm{K} 1, \ldots, \mathrm{Kn}$ as consequences?

How could $\mathrm{G}^{\star} / \mathrm{M}^{\star}$ not have $\mathrm{K} 1, \ldots, \mathrm{Kn}$ as consequences?

CQ2: Why should $\mathrm{K} 1, \ldots, \mathrm{Kn}$ be negatively valued?

How could $\mathrm{K} 1, \ldots, \mathrm{Kn}$ not be negatively valued?

\section{Argumentation Scheme 8. Argument from Operational Incompatibility (AS8)}

Premise 1: $\mathrm{G}$ is an objective already assumed by $\mathrm{X}$

Premise $2: G$ and $G^{\star} / M^{\star}$ are operationally incompatible

Therefore, plausibly

Conclusion: There is a reason for $\mathrm{X}$ not to assume $\mathrm{G}^{\star} / \mathrm{M}^{*}$

\section{Critical Questions for Argumentation Scheme 8}

CQ1: What reasons are there for taking $\mathrm{G}$ as an objective already assumed by $\mathrm{X}$ ?

What reasons are there for doubting $\mathrm{X}$ already assumed $\mathrm{G}$ ?

CQ2: What makes $\mathrm{G}$ and $\mathrm{G}^{\star} / \mathrm{M}^{*}$ operationally incompatible?

How could $\mathrm{G}$ and $\mathrm{G}^{\star} / \mathrm{M}^{\star}$ not be operationally incompatible?

Commentary: AS5 and AS6 are obviously the flip-sides to AS2 and conclude with reasons against assuming $G^{*}$. Similarly with AS7 with respect to AS3. In analogy to what I said regarding these, I do not see how AS7's premises can be true without AS5's being true, in which case there is no real need for both of them and only one reason can result from their both being appealed to rather than two. The critical questions, once more, aim at eliciting reasons why the premises may be true firstly and false secondly. 
Superficially, it might seem that CQ1 in AS5 and AS6 do question the choice of values on material grounds, which is the very thing I said does not happen. But as long as reasons can be given for the choice of values, I do not see that the questioner has any more to say, and when the value is an ultimate value, I do not see any very illuminating answer can be given to the question "What is your reason for valuing this?".

AS8 is the interesting argumentation scheme, and I think that it is unnecessary. First of all, you cannot get a reason to assume $G$ just because you actually have assumed $G$, and equally, you cannot get a reason to not assume $G^{\star}$ because it conflicts with some $G$ that you have assumed without reason (and Sàaua and Baumtrog are explicit that this is the kind of case that they are considering; otherwise, it would fall under one of the other three argumentation schemes). Insofar as there may be a reason here, it is only a subjective one.

What would happen if, because of operational incompatibility with such a $G$ (and for no other reason), we answered "No" to the question "Is $G^{*}$ compatible with other goals $G_{1}, \ldots$, $\mathrm{G}_{\mathrm{n}}$ that $\mathrm{X}$ has or should have?" Then we would be faced with the question "Is $\mathrm{G}^{*}$ preferable to G?" as the next topic question, and it seems to me that the answer to that question would always be "Yes", a goal that we have reason to have (as guaranteed by AS2/3) always being preferable to a goal that we have just assumed without reason. ${ }^{18}$ We only need to worry about the goals that we should have, as these are the only goals which provide us with objective reasons to act on them. So, we may as well eliminate the "has" from the "has or should have" in the first and second topic questions and answer "Yes" to the second topic question without worrying about what goals X actually has, thus eliminating AS8 (and AS1).

Now, it might be argued that insisting on this objective conception of reasons has illegitimately limited what we might engage practical reasoning on. After all, we do reason practically about how to achieve goals that we merely have whether we should have them or not, and we compare goals that we merely have with each other. True. But it is the attempt to integrate ethics with practical reasoning that has led to this limitation. Now, if we used subjective reasons all the way through, the model would, I think, still apply: AS1 will give us subjective reasons for goals (namely, our actually having those goals), these goals can be tested against each other, and the strongest subjective reasons will be the ones we act on and have a subjective reason to act on. So, we could not eliminate AS1 or consideration of goals we actually have, as long as we maintain also that the reason we end up acting on is subjective, and thereby allowing in all the kinds of acting that Sàaua and Baumtrog want on ethical grounds to rule out. Remember that a mere desire provides a subjective reason.

18 Note that CQ1 for AS8 does not establish that X assumed G for some reason, but only that there is reason to believe that $\mathrm{X}$ has assumed $\mathrm{G}$. 
a. Stage 2, Topic Question 3: Is $G^{*}$ preferable to the other goals !G1, . , !Gn that X has or should have? ${ }^{19}$

This is where the actual weighing of reasons for and against assuming goal $\mathrm{G}^{\star}$ takes place; it is "at this point where argumentation theory meets choice theory" (Sàágua and Baumtrog, 2018 , p.218). This is done by appeal to one argumentation scheme with two variants, depending on which goal is preferable.

\section{Argumentation Scheme 10. Argument Based on Rational Preference (AS10)}

\subsection{Variation in favour of $G^{\star} / M$}

Premise $1: ! \mathrm{G}$ and $\mathrm{G}^{\star} / \mathrm{M}^{\star}$ are contradictory.

Premise 2: $\left(R^{\star} \pm 1, \ldots, R^{\star} \pm n\right) G^{\star} / M^{\star}$.

Premise 3: $(! \mathrm{R} \pm 1, \ldots, ! \mathrm{R} \pm \mathrm{n}) ! \mathrm{G}$.

Premise $4:\left(R^{\star} \pm 1, \ldots, R^{\star} \pm n\right) G^{\star} / M^{\star}$ are preferable to $(! R \pm 1, \ldots, ! R \pm n) ! G$.

Therefore, plausibly

Conclusion: $\mathrm{X}$ should assume $\mathrm{G}^{\star} / \mathrm{M}^{\star}$ (and abandon !G)

\subsection{Variation in favour of !G}

Premise $1: ! G$ and $\mathrm{G}^{\star} / \mathrm{M}$ are contradictory

Premise $2:\left(R^{\star} \pm 1, \ldots, R^{\star} \pm n\right) G^{\star} / M^{\star}$

Premise 3: $(! R \pm 1, \ldots, ! R \pm n) ! G$

Premise $4:(! R \pm 1, \ldots, ! R \pm n) ! G$ are preferable to $\left(R^{\star} \pm 1, \ldots\right.$,

$\left.\mathrm{R}^{\star} \pm \mathrm{n}\right) \mathrm{G}^{*} / \mathrm{M}^{\star}$

Therefore, plausibly

Conclusion: X should assume! $G$ (and abandon $G^{\star} / M^{*}$ )

\section{Critical Questions for Argumentation Scheme 10}

CQ1: What makes the standard(s) used for the evaluation of the reasons associated with the goals/means the best for this situation?

Why might the standard(s) used for the evaluation of the reasons associated with the goals/means not be the best for this situation?

CQ2: What makes the standard(s) used to assess the probability or plausibility of the reasons used to justify the assumption of the goal/means and of the goal/means being assumed the best for this situation?

Why might the standard(s) used to assess the probability or plausibility of the reasons used to justify the assumption of the goal/means and of the goal/means being assumed not be the best for this situation? 
Commentary: First of all, because of AS6 any positive reason for $\mathrm{G}^{\star}$ will be a negative reason for !G, and mutatis mutandis for negative reasons, so Premises 2 and 3 contain effectively the same information. ${ }^{20}$ Second of all, I am not sure what to make of the critical questions here. According to Sàágua and Baumtrog (2018, p.218) "these questions are challenging the goodness in the reasons and the accuracy of the probability of success, respectively." Note that this differs from what we usually say, which is that we prefer the goal with the greatest expected utility, which is the value of the goal, and not the strength of the reason, multiplied by the likelihood of achieving the goal. Yet AS10 talks about which reasons are preferable in Premise 4, and about standards used for the evaluation of the reasons in CQ1. I fail to see what these standards are supposed to be. Certainly, we can talk about reasons and their strength having done the utility calculation, but this is on the grounds that we have most reason to attempt to satisfy those goals with the greatest expected utility. Hence, we can talk about reasons and utilities interchangeably to some extent, but I fail to see how we get to utilities, or the preferability of one goal to another, by evaluating reasons, or how one reason is preferable to another, unless it means a reason to achieve something whose utility is higher, other things being equal.

I think that tolerable sense can be made of what they say in this way. All objective reasons ultimately derive from a value. This is given by AS2, and I argued that AS3 could be reduced to AS2. The weight of the reason for assuming $G^{*}$ could then be taken as the conditional probability of achieving the value $\mathrm{V}+$ if we assume the goal $\mathrm{G}^{\star}$ multiplied by the value of $\mathrm{V}+$ itself. (Note, though, that this does seem to treat the reason for assuming $\mathrm{G}^{*}$ as a Pascalian kind of instrumental reason, as it is the weight of this kind of reason that corresponds to the conditional probability at issue, in which case it is AS2 and AS3 that are irrelevant to this calculation, and not, as I suggested earlier, AS4.) Wanting to remain neutral on how exactly $\mathrm{V}+$ is to be valued, and according to what kind of moral theory, Sàágua and Baumtrog ask only that the arguer be able to justify his choice-this is the point of CQ1. ${ }^{21}$ Also wanting to

20 Whatever other goals may be incompatible with $G^{*}$ will eo ipso be compatible with !G, and so on.

21 In short, they want to critically test the choice of moral standards without, however, dictating any substantive moral theory or principles. One wonders how much they can hope to achieve this way, provided that the reasoner avoids selfinconsistency. What Baumtrog wants to achieve is to make the practical reasoning of Anders Breivik unreasonable, or at least make it more difficult for extremists of all kinds to reason their way into performing acts of terrorism:

[W] hile there is no substantive moral assumption in the model, the model does assume that morals are a matter of reason. As such, it expects every perspective to be subject to the realm of reason. Thus, in the case where a moral is presented without reason, say on mere faith las opposed to reasoned faith which is a different storyl, any reason supporting an alternate moral would win the day even if only in a "1-0" reason victory. Where a conflict of morals occurs, genuine argumentation is expected to bring out the side with the strongest reasons supporting it at the time. Where opposing reasons are presented, the opposition is expected to be resolvable by recognized argumentative means. (Baumtrog, 2015, p. 123-4) 
remain neutral on whether a probability measure or some kind of plausibility measure is better to use, they ask only that the arguer be able to justify this choice too-this is the point of CQ2.

a. Stage 3, Topic Question 4: Are there means M1, .., Mn that are simultaneously necessary and sufficient for $\mathrm{X}$ to achieve $\mathrm{G}^{\star}$ ?

There are three argumentation schemes relevant to Stage 3 and this topic question.

\section{Argumentation Scheme 11. Necessary Condition Argument (AS11)}

Premise 1: X has the objective of realizing $\mathrm{G}^{*}$.

Premise 2:\{NM1, .., NMn $\}$ are necessary means for $\mathrm{X}$ realizing $\mathrm{G}^{*}$.

Therefore, plausibly

Conclusion: $\mathrm{X}$ has a reason to carry out $\{\mathrm{NM} 1, \ldots, \mathrm{NMn}\}$.

\section{Critical Questions for Argumentation Scheme 11}

CQ1: What makes it plausible that $\{\mathrm{NM} 1, \ldots, \mathrm{NMn}\}$ are necessary means for $\mathrm{X}$ realizing $\mathrm{G}^{*}$ ?

How could any of these means be suppressed while still allowing for the realization of $\mathrm{G}^{*}$ ?

\section{Argumentation Scheme 12. Sufficient Condition Argument (AS12)}

Premise 1: $\mathrm{x}$ has the objective of realizing $\mathrm{G}^{*}$.

Premise 2: If $x$ carries out $\{\mathrm{NM} 1, \ldots, \mathrm{NMn}\}$, then $\mathrm{x}$ realizes $\mathrm{G}^{\star}$.

Therefore, plausibly

Conclusion: $x$ has a reason to carry out $\{\mathrm{NM} 1, \ldots, \mathrm{NMn}\}$.

\section{Critical Questions for Argumentation Scheme 12}

CQ1: How does carrying out all of the necessary means guarantee the realization of $\mathrm{G}^{\star}$ ? How might $\mathrm{G}^{\star}$ remain unrealized despite carrying out the necessary means?

\section{Argumentation Scheme 4b. Argument from Ability (AS4b)}

Premise 1: $M^{\star}$ are necessary and sufficient (or at least sufficient) for $G^{\star}$.

Premise 2: $\mathrm{X}$ has the ability to realize $\mathrm{M}^{*}$.

Premise 3: X's ability to realize $\mathrm{M}^{\star}$ is a necessary/enabling condition for the realization of $\mathrm{G}^{*}$.

\footnotetext{
I do not find it obvious what Baumtrog's argument is for such optimism. Perhaps someone who takes a moral view on faith is thereby unable to give reasons in response to CQ1, and this makes his reasoning bad. Or perhaps it is the reasoners' failure to ask themselves this question in the first place during their reasoning that is some kind of vice which makes their acting unreasonable. At best, this rules out a very limited number of cases. I am not going to be saying much about this. I will make the technical point that, insofar as their intention is to extend their model to include evaluation of our reasoning about values, that evaluation occurs here in CQ1 of AS10.
} 
Therefore, plausibly,

Conclusion: There is a reason for $\mathrm{X}$ assuming $\mathrm{M}^{\star}$.

Critical Questions for Argumentation Scheme 4b (AS4b)

CQ1: How does $\mathrm{X}$ have the ability to realize $\mathrm{M}^{\star}$ ?

What could prevent $\mathrm{X}$ from realizing $\mathrm{M}^{\star}$ ?

CQ2: To what extent is the assumption of $\mathrm{M}^{\star}$ by $\mathrm{X}$ a necessary/enabling condition for the realization of $\mathrm{M}^{\star}$ ?

Is there any $y$ ( such that $y \neq x$ ) whose ability to realize $M^{\star}$ is a necessary/enabling condition for the realization of $\mathrm{M}^{\star}$ ?

Commentary: There is no Critical Question connected with Premise 1 in either AS11 or AS12 since this premise has been established in the earlier stages (assuming that "the objective of realizing $G^{\star}$ " is the same as assuming $G^{\star}$ as a goal, which $I$ have argued that in fact it might not be). Nor is there one in AS4b, which follows AS4a in this regard. As usual, the other Critical Questions elicit reasons for the other premises' being true. It should be observed that now we are talking, and rightly so, about instrumental reasons: assuming $\mathrm{M}^{\star}$ is a means to bringing about $\mathrm{G}^{\star}$.

While it is plausible that AS11 and AS12 both provide pro tanto reasons for X to carry out the means, neither individually provide reasons for answering "Yes" to the Topic Question. AS11 provides reasons for answering "Yes" to "Are there means M1, .., Mn that are necessary for X to achieve $G^{\star}$ ?", and AS12 provides reasons for answering "Yes" to "Are there means $M 1, \ldots, M n$ that are sufficient for $X$ to achieve $G^{\star}$ ?", but neither answer the question "Are there means $\mathrm{M} 1, \ldots, \mathrm{Mn}$ that are simultaneously necessary and sufficient for $\mathrm{X}$ to achieve $\mathrm{G}^{\star}$ ?" I think Sàágua and Baumtrog mean to say that both AS11 and AS12 must be appealed to, ${ }^{22}$ but you do not thereby get two reasons for answering "Yes" or two reasons for X to carry out the means. In fact, it seems to me that Topic Question 4 is redundant and that Stage 4 should consist only of Topic Question 5; as long as there are sufficient conditions for X's achieving $G^{*}$, then $X$ has reason to realise those conditions and proceed to the next stage, and it should be noted that both topic questions, on receiving the answer "Yes", go to the same Topic Question at Stage 4. Conditions that are simultaneously necessary and sufficient are just a special case of conditions that are sufficient. ${ }^{23}$

22 I am assuming that that it is the same means that are referred to by NM1 . . NMn in the instances of both AS11 and AS12. In other words, I am assuming that $X$ has a set of means and asks firstly whether these means are necessary, and secondly whether they are sufficient. If the answer to both questions is "Yes" then clearly these means are simultaneously necessary and sufficient.

23 The fact that certain conditions may be necessary, and a part of all sets of sufficient conditions, does not add anything land is not actually taken account of in the model anyway-the model only considers necessary conditions 
As for AS4b, like AS4a it concludes with an instrumental reason. Even on a more charitable construction, it should be clear that AS4b cannot license answering "Yes" to "Are there means $\mathrm{M} 1, \ldots$, Mn that are simultaneously necessary and sufficient for $\mathrm{X}$ to achieve $\mathrm{G}^{\star}$ ?”, or insofar as it does, it does so precisely because its first, unquestioned, premise is " $M^{\star}$ are necessary and sufficient (or at least sufficient) for $G^{\star *}$, in which case the other premises are redundant as far as answering the topic question is concerned. Perhaps what Sàágua and Baumtrog have in mind is that having established this premise by use of AS11 and/or AS12 (which do question this premise) X's having the ability to carry out the means gives $\mathrm{X}$ an extra reason to carry out the means. AS4b can appealed to in addition to AS11/AS12 but is useless otherwise. But if so then it seems to me that it belongs to a later stage, as it does not contribute in any way to answering the Topic Questions asked at Stage 3, which only concerns the existence of the means of achieving $\mathrm{G}^{\star}$, and not X's ability, or anybody else's, to carry out those means.

a. Stage 3, Topic Question 5: Are there means M1, .., Mn that are sufficient for $\mathrm{X}$ to realise $\mathrm{G}^{*}$ ?

There are two argumentation schemes here, one of which is once again AS4b. Here is the other:

\section{Argumentation Scheme 12. Sufficient Condition Argument (AS12G)}

Premise 1: $\mathrm{X}$ has the objective of realizing $\mathrm{G}^{\star}$.

Premise 2: If $X$ carries out $\{\mathrm{NM} 1, \ldots, \mathrm{NMn}\}$ and $\{\mathrm{SM} 1$ or, .., or $\mathrm{SMn}\}$, then $\mathrm{X}$ realizes $\mathrm{G}^{\star}$. Therefore, plausibly

Conclusion: $\mathrm{X}$ has a reason to carry out $\{\mathrm{SM} 1$ or, ..., or $\mathrm{SMn}\}$ (in addition to the reasons $\mathrm{X}$ may have to carry out $\{\mathrm{NM} 1, \ldots, \mathrm{NMn}\})$.

\section{Critical Questions for Argumentation Scheme 12}

CQ1: How does carrying out at least one of SMi, where SMi belongs to $\{\mathrm{SM} 1, \ldots, \mathrm{SMn}\}$ (in addition to $\{\mathrm{NM} 1, \ldots, \mathrm{NMn}\}$, if there are such) guarantee the realization of $\mathrm{G}^{\star}$ ?

How might $\mathrm{G}^{*}$ remain unrealized in spite of carrying out all of these means?

\footnotetext{
when they are at the same time collectively sufficient). Possibly Sàágua and Baumtrog are influenced here by Audi's (2006, pp.110-11) necessary condition schema and sufficient condition schema. However, for Audi a stronger reason ensues upon a necessary condition than a merely sufficient condition. In the case of the latter "[s]ome kind of prima facie judgment does follow, since S has some reason to A" which is even weaker than the (already weak) reason derived from the necessary condition (weak because achievement of an end may be made only marginally more likely on the satisfaction of its necessary condition). If the same kind of reason is to apply to both (i.e., to be the conclusion of both AS11 and AS12), it must be the weaker, and this seems to be the pro tanto reason they have insisted on throughout. In short, if they want the distinction between necessary and sufficient schemes to have any point, their schemes would need to have different conclusions and refer to different strengths of reason. But since the weakest kind of reason is all that is required to get to the next stage anyway, there is no real motivation for making the distinction, and so we may as well skip Topic Question 4.
} 
Commentary: I would point out a certain ambiguity in AS12G's formulation. Is SM1 a sufficient condition in itself (in which case it already includes all the necessary conditions) or is it whatever further condition has to be added to the necessary condition in order for the conditions to be jointly sufficient? I think they intend the latter, for otherwise it would make no sense to say that $\mathrm{X}$ has a reason for SM1 (for example) that is additional to the reasons for NM1 ... NMn (as one would end up double-counting reasons); also, it seems to be an implication of CQ1. The next ambiguity is in the conclusion and concerns the scope of the reason. Is the reason a reason for the disjunction (and not necessarily for each disjunct) or for each disjunct? If SM1 is the kind of condition that I have just mentioned, then $\mathrm{X}$ does have a pro tanto reason to carry it out. The same applies to SM2 and SM3, and so on. Which of the 'sufficient' conditions one ends by having a conclusive reason to bring about will depend on further factors (and there may not necessarily be a uniquely best condition to bring about), but that is the nature of pro tanto reasons. ${ }^{24}$ I think that this is probably what Sàaua and Baumtrog intend. Even so, it seems to me that the whole thing is redundant, as the Topic Question is simply Premise 2 in AS12G, just as Premise 1 was in AS4b! Answering CQ1 amounts to answering Topic Question 5 without any help from the argumentation scheme.

a. Stage 4, Topic Question 6: Are the selected means M1, .., Mn compatible with the objectives $\mathrm{G} 1, \ldots, \mathrm{Gn}$ that $\mathrm{X}$ has or should have?

There are four argumentation schemes here: AS5b, AS6b, AS7b, AS8b. These are the same as AS5, AS6, AS7, and AS8 except instead of goals being incompatible with other goals, it is means (the set M1, . , Mn selected by the previous reasoning). ${ }^{25}$ One wonders how exactly means can be incompatible with, or preferable to, goals, and whether this is really distinct from the kind of considerations at issue in Stage 2. However, consider that there may be three distinct ways of bringing about $\mathrm{G}^{*}$, and while the first one $\mathrm{M} 1$ inhibits the achievement of goal $\mathrm{Gn}$, the other two do not. Therefore, $\mathrm{G}^{*}$ itself is compatible with $\mathrm{Gn}$ but $\mathrm{G}^{*}$-ing by M1-ing is not compatible with $\mathrm{Gn}$, that is to say, $\mathrm{G}^{\star}$ and $\mathrm{Gn}$ cannot both be achieved if the means chosen to achieve $G^{\star}$ is M1. It makes sense, then, to compare means with goals as well as to compare different goals. Sàágua and Baumtrog conceive of this as operating itera-

\footnotetext{
24 Suppose that one has a reason for satisfying a disjunction, and that reason is not pro tanto. It seems to me that one then has a pro tanto reason (though not a non-pro-tanto reason) for satisfying any of the disjuncts-it is a consideration in any of the disjuncts' favour that by satisfying it one satisfies the disjunction. Distribution of reasons across the disjunction to the disjuncts is valid when the reasons so attached to the disjuncts are pro tanto, whether the reason for the disjunction itself was pro tanto or not.

25 This was indicated in those schemes using the device $\mathrm{G}^{*} / \mathrm{M}^{*}$. $\mathrm{G}^{*}$ referred to the goal and was the thing in question in those earlier stages. The variants being discussed at this stage take the $M^{*}$ side, $M^{*}$ referring to the selected means.
} 
tively, so that a means that is incompatible (like M1 in the example) is excluded from further consideration if there is another that is not incompatible. Only if all the possible means are incompatible do we need to decide which is preferable. But, if this is the case, then I do not see how $\mathrm{G}^{\star}$ can be compatible with $\mathrm{Gn}$ when all the possible means of achieving $\mathrm{G}^{\star}$ are incompatible with $\mathrm{Gn}$. And if this is right, then there will always be a means of achieving $\mathrm{G}^{*}$ that is compatible with Gn. It is tempting then to think that an affirmative answer to Topic Question 6 is guaranteed by affirmative answers to Topic Questions 3 and 5. But I don't think so, for the reason that while there must be a means of achieving $G^{\star}$ that is compatible with $\mathrm{Gn}$, there may not be a single means that is compatible with all the goals $\mathrm{X}$ should have. Suppose that M2, which is compatible with $\mathrm{Gn}$, is incompatible with Gm which is not itself incompatible with $\mathrm{G}^{\star}$ but would be preferable if both $\mathrm{G}^{\star}$ and $\mathrm{Gm}$ could not both be brought about, which would indeed be the case if $\mathrm{G}^{*}$ is brought about by $\mathrm{M} 2$. Although for each goal Gi incompatible with a means to $G^{*}$ there must be another means to $G^{*}$ that is compatible with $\mathrm{Gi}$, there may not be a means that is compatible with every such $\mathrm{Gi}^{26}$

Commentary: Obviously, everything I said about the AS5, AS6, AS7, and AS8 apply equally to AS5b, AS6b, AS7b, and AS8b. The basic idea seems to be that if we can carry out the means without thereby doing something that is incompatible with a goal that we ought to have, then we can go ahead and do it. Thus, an affirmative answer to this Topic Question leads at stage 5 to the directive "Take Action." X has a pro tanto reason to assume $G^{*}$ (established at Stage 1) and, because of this, a pro tanto reason to carry out a selected means M1 ... Mn (established in Stage 3) to achieving $G^{*}$ and no pro tanto reasons not to carry out this means. If I have a criticism here it is that I think that X's ability to carry out this means (mentioned in regards to AS4b) ought to come in here-plausibly, if X does not believe that he can carry out the means, his reasoning should not make it incumbent upon him to carry it out. Something has gone funny with your reasoning if it leads you to try to carry out actions that you do not believe yourself able to carry out (even if, in fact, you are able to carry them out). Ability has to figure into practical reasoning somewhere, but not where Sàágua and Baumtrog put it. Believing that you can do it does not create an extra reason for you to do it (except, possibly, instrumentally), but believing that you cannot do it does create a reason for you not to attempt it.

a. Stage 4, Topic Question 7: Are the selected means M1, .., Mn preferable to the goals $\mathrm{G} 1, \ldots, \mathrm{Gn}$ with which they are incompatible?

26 The difference is between "For every goal Gi compatible with G*, there exists a means Mi for achieving goal G* that is compatible with Gi" and "There exists a means Mi for achieving goal G* that, for every goal Gi that is compatible with $\mathrm{G}^{*}, \mathrm{Mi}$ is compatible with $\mathrm{Gi}^{\prime}$. Only the first is true, whereas the reasoning being rejected requires the second. 
There is one argumentation scheme here: AS10b. This is the same as AS10 except where AS10 talks about the preferability of goals over other goals, AS10b talks about the preferability of means over other goals. Only if all the means M1, .., Mn are incompatible with a goal X should have is this Topic Question asked (Sàaua and Baumtrog, 2018, p.226).

Commentary: The obscurity of how exactly the weighing of reasons is supposed to take place recurs here. It is simply stated in Premise 4 of the scheme which is preferable out of the assumed goal/the selected means and the goal that is incompatible with this, and the conclusion says little more than to prefer the preferable. Perhaps the idea is that as long as X's choice of preferability relation is not unreasonable then, even if it is wrong and a different relation is objectively better suited to the task, X's wrongness is not that of bad practical reasoning.

\section{a. Stage 5}

There is no topic question here. Traversing the model is to result in taking action or not taking action, for the reasons generated by the argumentation schemes appealed to in the earlier stages.

Commentary: I will repeat here my skepticism about how a reason that is only pro tanto can license acting in this stage. Again, I think that the idea is meant to be that when we have established at Stage 4 that there is a set of means that is compatible with the preferable set of goals, this makes the reasons for those means conclusive. This would mean in effect that the argumentation schemes used at Stage 4 do not generate pro tanto reasons at all but all things considered reasons, reasons that could then be detached and taken to license acting, or at least be a reason to form that intention. But the problem that remains is that by Sàágua and Baumtrog's account this is all contextual, and, taking the model as a model of argumentation, relative to a dialectical situation. It is quite possible then for the same arguer to be at the same time in a context or dialectical situation where such an action was not licensed or even prohibited, and even if that is not the case at the current moment, he knows that he could be in that situation. Is his acting then justified overall? He can give reasons for his acting that would be acceptable to a particular set of interlocutors, certainly, but it might still be wiser to wait than to act.

\section{Conclusion}

"If we are to be responsible academics, we must then justify the need for our current contribution; we must answer the question 'What is on offer here that cannot be found elsewhere?" Sàágua and Baumtrog ask, and answer that "the new model is an integrated 
model of practical reasoning and argumentation" which they then cash out by saying firstly that its components can be interpreted in term of reasons in an inferential process or as commitments in an argumentation, and then by saying that argumentation schemes should be interpreted in a way such that their conclusions are (pro tanto, contributing) reasons. These two claims are in conflict: if it is built into the formal structure of the argumentation scheme that its conclusion is a reason, then I do not see how it can be re-interpreted as a commitment. Certainly, we can reason as well as argue using argumentation schemes, but only because their formal structure does not dictate them being interpreted one way or another; it is only insofar as reasonings and argumentations have the same structural elements that re-interpretation is possible. All models of reasoning and argumentation are integrated to this extent, so it can hardly be claimed by Sàágua and Baumtrog to be a special virtue of their model that it does this too, and by building reasons into the formal structure of the scheme it is not clear that they can even claim this virtue. Also, when we do reason using argumentation schemes, we do not reason about what reasons we have; building reasons into the formal structure of the scheme gives an unnatural view of reasoning as second-order reasoning about our reasons when used as a model of reasoning. So, their model is not even as integrated as other models and is unnatural as a model of reasoning. Yet this is the only really original part of their proposal, as otherwise their model is no better than other models, which is to say that they would not be offering anything in their model that would not be found elsewhere and by their own account they would be irresponsible academics.

Nor are they even consistent in their use of pro tanto reasons. They fail to distinguish between the instrumental reasons that are properly the subject of discussion in Stages 3 and 4 from the objective moral or normative reasons that seem to be at issue in Stages 1 and 2, and this causes them to miscount the number of reasons in favour of assuming $\mathrm{G}^{\star}$. I have also explained, in connection with this, that it would be better to consider only the goals $\mathrm{X}$ should have and not those that X just has. Also, at stage 3 there is a mismatch between the conclusions of the Necessary and Sufficient Condition Arguments and the topic question they are intended to answer. The pro tanto reason concluded in the Necessary Condition Argument is that there is a reason for $\mathrm{X}$ to carry out what is necessary, and not to answer "Yes" to "Are there means M1, .., Mn that are simultaneously necessary and sufficient for $\mathrm{X}$ to achieve $\mathrm{G}^{\star}$ ?" Obviously, we cannot answer "Yes" using only this argumentation scheme because the scheme only concerns necessary conditions. Sàaua and Baumtrog would argue that we have to apply the schemes sequentially so that when we have applied the Sufficient Condition Argument as well, we have a set of necessary conditions that are jointly sufficient. Even so, the conclusion is once again to carry out these means and not to answer "Yes" to "Are there means $\mathrm{M} 1, \ldots, \mathrm{Mn}$ that are simultaneously necessary and sufficient for $\mathrm{X}$ to 
achieve $G^{\star}$ ?" Also, there may not be any means that are necessary for $\mathrm{X}$ to achieve $\mathrm{G}^{\star}$, so really the topic question should be more simply "Are there means M1, .., Mn that are sufficient for X to achieve $G^{\star}$ ?" as in Topic Question 5. It is true to say that one can answer "Yes" to this question, but only because Premise 2 of the Sufficient Condition Argument AS12G

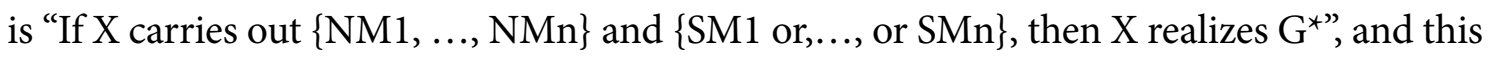
is only another way of saying that these means are sufficient for $X$ to achieve $G^{*}$ ! In other words, Premise 2 simply says that you can answer "Yes" to the topic question. Hence, not only can we use the Sufficient Condition Argument and eliminate the Necessary Condition Argument, we do not even need all of the Sufficient Condition Argument but only its second premise and possibly the critical questions associated with testing this premise. Stage 3 more or less vanishes. Finally, I have argued that they implicitly treat the reasons produced at stage 4 to be all things considered reasons and not pro tanto reasons at all; if they really are pro tanto reasons, I don't see why someone who has such a reason could not say "Well, I'll wait and see. My reasons are only pro tanto after all, and only follow defeasibly on my premises and provisionally on my current context. I don't want to act and then find myself in a context where it would have been better not to act." Only if there is a necessity to act immediately would such an agent be rationally motivated to act. ${ }^{27}$

This is not to say that the argumentation schemes in Sàágua and Baumtrog's model are complete rubbish. I would argue, though, that their plausibility relies entirely on their resemblance to reason transmission principles, to which Sàaua and Baumtrog have nothing original to add and even seem unaware of the controversies regarding the formulation of such principles; for example, the schemes all seem to be narrow-scope rather than wide-scope. ${ }^{28}$ It is because of the resemblance of the argumentation schemes to such principles that makes expressing their conclusion as reasons superficially attractive. Nonetheless, it is an error of an extremely fundamental sort, and not only but not least because this makes it powerless to resolve at least a core kind of conflict (i.e, where there are pro tanto reasons on both sides). Also, such principles are descriptions from an external third-personal viewpoint of what

27 Would it make a difference if one were arguing only with oneself? At (2018, p.196) Sàágua and Baumtrog say: "Only when someone reasons or argues by himself, does the argumentation immediately result in an intention to perform the action (or not)." But I don't think this avoids the objection if the inference is only defeasible. Suppose that you conclude that Tweety flies because it is a bird: although you know that there are penguins and other flightless birds, you are in a state of ignorance about whether Tweety is one of these kinds of birds, and you know that you are in such a state of ignorance. It is not obviously irrational to wait and try to answer this question before committing yourself to the conclusion. Moreover, it seems plausible that you do have a pro tanto reason to think that Tweety flies on the grounds that it is a bird and birds generally fly land if so the inference is not actually defeated after all, at least if the conclusion is that there is such a pro tanto reason) but again it is not obviously irrational to hold fire on committing oneself on whether Tweety flies.

28 This is despite claiming the influence of Broome, who is one of the most notable arguers for the wide-scope view. I think this is possibly due to the influence of Fairclough and Fairclough (2012) as explained in footnote 14. 
objective reasons someone has or what subjective reasons someone ought to have if they are rational, and does not describe reasoning itself, whether our own or even that person's. We do not reason using Reasoning Modus Ponens but by using modus ponens. A model that uses such principles, then, is not a model of practical reasoning as such, or at least it is not a model of first-order reasoning but treats practical reasoning as second-order reasoning. ${ }^{29}$

An integrated model of reasoning and argumentation is a false ideal, because reasoning and argumentation have different norms. A model should be integrated to the extent that a piece of reasoning is structurally identical to a piece of argumentation. But Sàágua and Baumtrog's model fails to be even as integrated as this because of their misjudged attempt to put reasons into the formal structure of the argumentation schemes, and this resists any re-interpretation in terms of commitments. Far from being able to justify its existence on the grounds of its integratedness, as they claim, their model is a disaster on this count. But if they recanted on this point, then the best that could be said for their model is that it was no worse than other models; their reconceptualization of argumentation schemes is their one real claim to novelty, and without it their own justification for the model collapses. Nor do they seem able to offer anything beyond traditional utility/choice theory as a way of weighing which goals to pursue, except to re-express the same problem in a confusing way as the weighing of reasons, whereas the weight of reasons can only be seen as a way of expressing the output of the utility calculation and not its input. In fact, it is a premise of their argumentation schemes at this stage that one set of goals is preferable to another, and not something that the schemes conclude.

Of the two ways in which their model is extended - the evaluation of the choice and/ or preference-ordering of values, and its being applicable to both reasoning and argumentation - the second has turned out to be a disaster, and it is what I have focussed on in this paper. I have not said much about the first, and reasons of space forbid my doing so here. Baumtrog believes that we can argue about values, but ironically it is not clear whether this is anything more than an article of faith on his part. I would suggest that he pose the same critical question to himself: what reasons can I give for the claim that disagreements about values can be resolved rationally that are acceptable to someone who does not believe this?

29 Admittedly, one could have first-order reasoning by following such transmission principles, e.g., by saying in the second-order account that because one believes that there is objective reason for the goal, and in such a case there is objective reason for the means, one should also believe that there is objective reason for the means; in other words, the objective reasons become part of a first-order reasoning las usual, the attitude drops out of the first-order account, making the objective reason analogous to $p$ in an ordinary modus ponens-the reasoner takes there to be an objective reason $R$ just as he takes $p$ to be true). Even so, it would not be very natural. We do not in general reason about what reasons we have until that point where we wish to weigh reasons against each other, which is not what we are talking about here. 
Without making substantive moral judgments about the Nazis' belief system, can we really conclude that they were unreasonable and/or guilty of bad practical reasoning? Setting aside those cases where we can trap such reasoners in self-inconsistencies, it is not obvious to me that we can.

But even if more belief systems are internally incoherent than I am supposing, it locates the error in the wrong place; it would be like objecting to torture not on the grounds that it is morally wrong but because it is not actually effective in getting people to tell the truth, that is to say, torture is objectionable on empirical grounds because torturers are factually mistaken about its effectiveness as a means; moreover, I do not see that the Nazis were wrong in any comparable way about the effectiveness of using Zyklon B to gas Jews. We want to say more about such cases that they made a mistake in inference or held beliefs on insufficient evidence! We do not want to allow an easy escape from a moral vice into an epistemic vice. We want to say that they are morally wrong and not just that they fell short of some ideal of rationality which we all fall short of very frequently! I suspect that this is the conclusion that the authors are aiming for and their rationale for adopting an objective conception of reasons, which is to say, ironically, that they have themselves chosen a means inappropriate to their ends: no criticism that does not make substantive moral assumptions has the means to evaluate an argument as having morally wrong premises or conclusions. At best critics can show that it results from bad reasoning, but to be guilty of bad reasoning somewhere is clearly a much less serious charge. Having an objective conception of reasons will only serve the end of evaluating the practical reasoning as bad if those evaluating the reasoning are allowed to criticise those reasons on material grounds. By their reluctance to make any such criticism, they may as well have stuck with a subjective conception of reasons, as indeed most models of practical reasoning do, since they take as their target instrumental reasoning and we reason instrumentally whenever we have a desire which we then reason about how to fulfil.

Sàágua and Baumtrog are guilty of bad practical reasoning: they choose means inappropriate to their ends. They choose a means to integration which I have argued is actually counter-productive for that purpose, namely re-conceptualizing schemes as having pro tanto reasons as conclusions. They rightly choose an objective conception of reasons in order to rule out certain choices of ends, but undermine this by including goals that the reasoner actually has (and in which objective reasons are not involved, although it seems that they fail to notice this) as well as those he should have (which do) as determining which actions to perform, allowing in the limit case where there are no conflicting goals the very choice of ends that they want to rule out as unreasonable. Finally, by choosing not to make any substantive moral assumptions of their own and thereby disallowing any challenge to 
premises on the grounds of their material truth, the only criticism Sàaua and Baumtrog are allowed to make of a morally invidious choice of ends is that the agent is inconsistent and/or unreflective and not that they are immoral.

\section{References}

Audi, R. (2006). Practical Reasoning and Ethical Decision. New York: Routledge.

Baumtrog, M. (2015). Improving practical reasoning and argumentation. Doctoral Thesis.

Fairclough, I., \& Fairclough, N. (2012). Political Discourse Analysis: A Method for Advanced Students. London: Routledge.

Hitchcock, D. (2016). Commentary on Baumtrog's "Investigating the Impact of Moral Relativism and Objectivism on Practical Reasonableness". In D. Mohammed \& M. Lewiński (eds.) Argumentation and Reasoned Action: Proceedings of the 1st European Conference on Argumentation, Lisbon, 2015. Vol. I, pp.47-51. London: College Publications.

Sàágua, J. and M. Baumtrog. (2018). Practical rationality at work - a new argumentation model. In Essays on Value and Practical Rationality, eds. A. Marques and J. Sàágua, pp.193-230. Bern: Peter Lang International Academic Publishers. 